\title{
A Pilot Study on the Anxiety Reduction Effect of Tension, Stress, and Trauma Releasing Exercises (TRE)
}

\section{긴장·스트레스·트라우마 완화 운동(TRE)의 불안감소 효과에 대한 pilot 연구}

\author{
Juwon $\mathrm{Oh}^{1}$, Cha Sun Shin ${ }^{2}$ \\ 오주원 ${ }^{1}$, 신차선 ${ }^{2}$ \\ ${ }^{1}$ Assocaiate Professor, Department of Counseling Psychology, University of Brain Education, Korea, \\ juwon@ube.ac.kr \\ ${ }^{2}$ CEO, Peace to People, Korea, sinchasun@daum.net
}

Corresponding author: Juwon Oh

\begin{abstract}
The purpose of this study is to examine the principles and mechanisms of a unique exercise method known as Tension Stress Trauma Releasing Exercises (TRE) and to explore whether TRE relieves adult state anxiety. Physical tremors are generally physical symptoms experienced during or immediately after experiencing excessive tension, stress, and trauma. In this study, TRE was briefly introduced and a pilot study was conducted first before starting to verify the effect in earnest by applying a structured experimental design. The subjects of the study were 25 graduate students who participated in the training. The condition anxiety test was performed before and after training for the group who received 3 hours of TRE training, and the paired-t test was applied for data processing. As a result of the study, it was found that TRE body tremor exercise reduces state anxiety. The results of this study indicated that TRE tremors have an anxiety reduction effect and suggested the possibility of therapeutic values for various physical and psychological difficulties.
\end{abstract}

Keywords: TRE, Physical Tremors, Neurogenic Tremors, Tension, Stress, Trauma

요약: 연구의 목적은 긴장, 스트레스 및 트라우마 완화 운동(TRE: Tension Stress Trauma Releasing Exercises)으로 알려진 독특한 운동법의 원리 및 기전을 고찰하고 TRE가 성인의 상태 불안을 완화하는지를 탐색하는 것이다. 본 연구에서는 TRE에 대해 간략히 소개하고 구조화된 실험설계를 적용하여 본격적인 효과 검증에 착수하기 전에 먼저 pilot 연구 형식으로 진행되었다. 연구대상은 훈련에 참가한 대학원생 25명이다. 3시간의 TRE 훈련을 받은 집단을 대상으로 훈련 전과 후에 상태 불안검사를 실시하였고, 자료처리는 SPSS 21.0 version을 사용하여 paired-t검증을 적용하였다. 연구결과, 신체를 떠는 운동법인 TRE는 상태 불안을 감소시키는 것으로 나타났다. 이러한 본 연구의 결과는 TRE 떨림이 상태 불안을 감소하는 효과가 있음을 나타내며 다양한 신체 및 심리적 어려움에 대한 치료적 가치의 가능성을 시사한다.

핵심어: TRE, 신체 떨림, 신경성 떨림, 긴장, 스트레스, 트라우마

Received: June 28, 2021; $1^{\text {st }}$ Review Result: August 16, 2021; $2^{\text {nd }}$ Review Result: September 30, 2021 Accepted: October 31, 2021 


\section{1. 서론}

스트레스는 현대를 사는 우리에게 피할 수 없는 일이다. 적당한 정도의 스트레스는 오히려 우리의 삶에 활력을 주는 자극제가 되기도 하지만 감당할 수 있는 스트레스의 양을 초과하여 발생하는 심리적 위기 상태인 트라우마의 경우는 개인에게 매우 치명적인 영향을 미친다.

그간 심리학적으로 다루어져 왔던 트라우마 치료는 어려운 심리치료로 분류되고 있는 실정이다. 그러나, 최근에는 뇌과학의 발전에 따라, 트라우마가 생길 때의 뇌 활동, 트라우마가 치료되기 전후의 뇌 변화 등이 신경생물학적으로 밝혀지고 있다. 최근까지 밝혀진 바에 의하면 트라우마는 본능과 무의식을 관장하는 뇌의 편도와 뇌간과 밀접한 관련이 있다. 편도 및 뇌간에 저장된 트라우마는 정서, 신체감각이나 이미지 등으로 조각조각 분산되어 저장된다. 이러한 조각 기억들은 생활하면서 이를 연상시킬 수 있는 작은 단서들을 만날 때, 이 기억이 촉발되어 트라우마의 정서와 감각을 재경험하게 된다. 트라우마 사건은 일회성으로 끝나지만, 시간이 흐른 뒤에도 비슷한 상황을 만나게 되면 그때의 그 감정과 감각이 그대로 되살아나 고통을 경험하게 된다.

최근의 신경과학 연구들은 정신분석이나 인지치료 같은 언어중심 치료법들이 PTSD(posttraumatic stress disorder) 및 외상에 효과적이지 않은 이유를 설명하며, 정신 생리학적인 접근을 통한 치료적 요법들이 요구됨을 밝히고 있다. 신경과학 연구들은 인간이 자신의 행동과 감정에 대해 의식적으로 통제하는 데에 상당한 한계가 있음을 보여준다[1]. 트라우마를 겪은 개인에게는 중추신경계의 본능적이고 무의식적인 생리학적 과정들이 활성화되며 신피질 과정은 무시되고 감소한다는 것이 확인되었다[1][2]. 트라우마는 잠재적으로 트라우마 사건 동안 신피질 과정과 사회적 참여 시스템(social engagement system)이 차단되어 사건 이후에도 정상적으로 돌아올 수 없을 때 발생한다[1-3]. 이로 인해 마음챙김(mindfulness)과 상향식(bottom-up) 신체 지향 심리 요법(BOP: body oriented psychotherapies)에 대한 관심이 PTSD치료에 포함되기 시작하였다[1][4][5].

BOP의 중요성은 Focusing[6], Gestalt 치료[7], Bioenergetic Analysis[8] 및 기타 여러 접근 방식에서 오랫동안 인식되어 왔다. 그러나 최근에 와서야 효과를 검증하는 연구가 등장하기 시작했다. $\mathrm{BOP}$ 연구 및 증거 기반 임상에 대한 최근 검토에서 Rohricht는 BOP가 신피질 기반 정신 요법에 잘 반응하지 않는 신체형 장애, PTSD 및 만성 정신분열증과 같은 상태에 도움이 된다는 것을 발견했다[1][2].

기존의 치료법들과는 다른 이러한 새로운 경향성들이 있음에도 불구하고, 반복적인 외상은 가장 심각한 정신 질환과 관련이 있으며, 전쟁과 자연재해로 인한 대량 외상은 증가하고 있지만 많은 사람들이 치료 비용을 감당하거나 치료 시간을 낼 여유가 없다는 측면, 또한 증가하는 수요를 충족할만한 충분한 치료사가 부족하다는 측면에서 트라우마 및 PTSD에 대한 심리치료는 현재 위기라고 보여지며, 과도한 스트레스나 트라우마를 경험한 사람들이 빠른 시간 안에 회복될 수 있는 효과적인 치료를 제공하기 위한 패러다임 전환이 절실히 필요하다고 할 수 있다[9].

Berceli 박사는 야생동물들은 포식자의 공격에 정기적으로 노출되지만,그들이 가지고 있는 자연치유 방법의 하나인 ‘떨림(tremor)' 을 통해 긴장과 스트레스를 해소하기 때문에 외상 후 스트레스 장애가 발생하지 않는다는 사실에 착안하여, 긴장·스트레스·트라우마 해소 운동(TRE: tention stress trauma releasing 
exercises)을 개발하여 대규모 집단에 적용하게 되었다.

Berceli박사는 이 운동법을 전쟁으로 피폐한 아프리카 19 개 국가에서 15 년 동안 대규모 그룹에 적용하였으며, 지금은 그 효과의 탁월성을 인정받아 미국방 국방부뿐만 아니라 전 세계 50 여 개국에 소개되고 있다.

본연구의 목적은 Berceli박사가 개발한 TRE의 원리와 운동법에 대해 소개하고 간략한 pilot스터디를 통해 TRE가 성인의 상태 불안에 긍정적 영향을 미치는지를 탐색해보고자 하는 것이다.

\section{2. 이론적 배경}

\section{1 신경성 떨림(Neurogenic Tremors)}

많은 문화권에서 다음과 같은 말을 듣는 것은 흔한 일이다. '너무 긴장해서 온몸이 떨렸다', '발표를 할 때 손과 다리가 떨렸다', '너무 화가 나서 몸이 떨렸다' . 이러한 신체적 ‘떨림' 의 경험은 누구에게나 일어날 수 있는 일반적인 현상이기도 하면서 외상후 스트레스 장애, 공황발작, 사회공포증, 범불안장애 진단의 단서이기도 하다. 이러한 떨림은 스트레스가 많은 상황에 대한 신경학적 반응이므로 신경성 떨림으로 가장 잘 정의된다. 떨림은 인체의 유전적 구성의 일부인 뇌의 절차적 기억 시스템의 자연적 과정에서 비롯된 원시적 신체 경험이다[10].

신경성 떨림은 인간 유기체가 항상성을 회복할 수 있는 타고난 적응 메커니즘으로 가정된다. TRE 운동법의 창시자인 Berceli[11]는 이러한 떨림이 자율신경, 변연계 및 뇌간 회로에서 발생하며 스트레스와 외상의 경험에 반응하여 본능적으로 활성화된다고 주장한다. Berceli는 신경성 떨림이 치료적으로 활성화되어 불완전하거나 조절되지 않는 스트레스 반응을 방출할 수도 있다고 제안한다.

신경성 떨림의 물리적 감각은 가장 일반적으로 근육의 약한 진동 또는 떨림이다. 근육의 떨림은 운동 수행 분야에서 신체의 생리적 반응[12]으로 언급되었지만, 이러한 떨림의 심리 치료적 가능성이나 가치에 대해 가장 광범위하게 저술한 두 신경학자는 Robert Scaer[10]박사와 Peter Levine[13]박사이다. 이들은 인간이 떨림에 대해 사회화되어 떨림을 억제한다고 믿는다. 자연적으로 발생하는 반응인 떨림은 불편하고 '통제할 수 없는' 행동으로 경험되기 때문에 사회적으로 용인될 수 없는 것으로 간주하여 피해야 하는 것, 심지어는 약, 알코올 또는 다른 물질을 통해 이를 마취 시켜 버려야 하는 것으로 인식되어 왔다[13].

스트레스 요인에 대한 잠재적인 치료적 반응으로서의 떨림에 대한 연구는 Selye[14]에 의해 동물에서 처음으로 연구되었다. 그의 연구는 동물이 자연스러운 떨림을 가지고 있음을 보여주었다. 그는 이러한 떨림이 스트레스를 받거나 충격적인 사건에 따른 반응이며, 동물에게 적응적 이점이 있는 것으로 보인다는 것을 발견한 최초의 연구자이다.

동물 연구자에 따르면, 야생 동물에서 이 떨림 메커니즘은 외상 후 스트레스 장애(PTSD)에 대한 면역을 기본적으로 제공하여 PTSD 증상을 나타내지 않고 정상 생활로 돌아갈 수 있도록 한다[13]. 인간은 생명을 위협하는 사건 후에 무의식적으로 떨릴 수 있지만, 이는 인간이 사회화 되는 과정에서 두려움의 증상이나 약점의 표시로 간주한다[15]. 또한, 위협적이지 않은 상황에서 떨림이 발생하면 병리적인 것으로 간주한다. 간질 발작, 파킨슨병 떨림, PTSD 및 비간질 발작(non-epileptic seizures)을 
포함한 불안 장애는 사회화가 이를 억제한 것으로 보인다[16].

Levine의 연구는 이러한 새로운 이론을 뒷받침하는 다양한 증거들이 있다. 몸을 떠는 행동 후에 아편 물질이 감소한다는 사실과, 떨림이 두려움보다 회복에는 더 효과적이라는 사실을 시사한다. 마찬가지로, 병아리가 위협을 받고 충분히 날개를 흔들고 퍼덕거리는 행동을 하기 전에 다시 위협을 받은 병아리는 생존 능력이 감소되는 것으로 밝혀졌다[3].

인간의 경우, 중국의 기공 교사(Chi Gong teachers)는 떨림을 포함한 자발적인 신체 운동이 심리적 증상을 완화한다고 수천 년 동안 주장해 왔다. 또한, 생체 에너지 분석[8], 감각 운동 심리 치료[5], 신체 기반경험요법[13] 같은 많은 신체기반 정신 요법(BOP)은 진동이나 떨림을 치료로 인식한다.

이러한 기존의 연구을 종합하면, 자연적으로 발생하는 떨림이나 유도된 떨림이 치료적일 가능성이 있다는 다양한 실질적인 증거들이 있다.

\section{$2.2 \mathrm{TRE}$ 운동}

Berceli가 개발한 TRE운동법은 아프리카 및 중동에서 대규모로 적용이 되었으며 그가 축적한 일화적인 증거들에 따르면, 이 운동법은 안전했으며, 많은 사람들이 수면 장애, 과장된 놀람 반응, 과민성, 불안한 기억 및 분리와 같은 PTSD에서 일반적으로 경험하는 과각성 증상을 감소시킨 것으로 보고하고 있다. 이들은 다양한 문화적, 종교적 배경을 가지고 있었으며 이러한 피드백은 민간인들이나 군인들 모두에게 똑같이 긍정적이었다.

서부로 돌아온 후 Berceli는 몇 가지 pilot 연구에 착수했다. 그는 TRE가 미국 10대 학생들의 수면의 질을 개선하고 스트레스를 감소시킨다는 증거[11]와 기관 인턴십을 하는 사회복지사 학생들의 3 가지 스트레스 측정치를 유의미하게 감소[17]시켰다고 보고했다. 또한, 무작위 통제 연구(a randomized controlled study)에서 그는 TRE가 대조군과 비교하여 대학생의 불안을 줄인다는 사실을 발견했다[15]. 미국 육군에 대한 연구가 진행 중이며 TRE가 전투 부대의 스트레스를 줄이는지 여부에 대한 보고서가 계류 중이다.

이 운동은 근육을 활성화시키기 위한 목적을 갖는 6가지 운동과 실제 떨림을 경험하는 마지막 운동으로 구성된다. 한 발로 서 있는 동안 발꿈치를 올리고 내리기, 바닥에 발을 평평하게 놓고 한 발로 서서 체중을 지탱하는 무릎을 구부렸다 펴기, 벽에 기대기, 눕기 등과 같은 간단하고 안전하며 쉬운 동작을 포함한다. 무릎을 구부린 상태로 바닥에 눕는 것이 일반적인 최종 떨림 자세이다. 이러한 운동은 개인의 신체 건강, 체력, 연령 및 유연성에 따라 다소 변경될 수 있다. 약간의 통증이라도 느끼면 즉시 운동을 중단하도록 지시한다. 대부분의 사람들은 적어도 3 개월 동안 15 분 동안 일주일에 두세 번 떨림을 연습하고 대부분의 활성화 운동 6가지를 적어도 일주일에 한 번 수행하도록 안내받는다.

Berceli[11]는 자신의 기술을 진화적 적응의 이론적 틀 안에 두고 생물학, 신경 생리학, 인지 신경 과학, 신체 심리학 및 외상학을 포함한 다양한 분야의 연구를 활용하여 신체를 통한 회복에 대한 기본적인 생리학적 근거를 제시한다. 그는 인간 종의 타고난 생존 메커니즘과 이러한 메커니즘이 어떻게 잘못되어 왔는지에 초점을 맞추는 회복을 주장한다. Levine[13] 및 Scaer[10]와 함께 Berceli[11]는 떨림이 실제로 인간이 공유하는 타고난 적응 메커니즘이라고 주장한다.

$\mathrm{TRE}$ 는 특정 근육 그룹을 피로하게 하기 위해 고안된 매우 간단한 운동 기술이다. 
Koch[18]는 핵심 근육인 장요근(illiopsoas)인 주굴근(the chief flexor muscle)에 대해 자세히 설명한다. 요근의 역할은 모든 취약한 부분(생식기, 중요한 장기, 머리, 눈, 귀, 코, 입)을 보호하기 위해 개인의 사지를 함께 태아자세로 수축하여 보호하는 것이다. 이러한 수축을 '굴근 철회(flexor withdrawal)'라고 한다. 이렇게 수축된 근육은 스트레스 반응이 끝나면 신체가 항상성을 회복하고 모든 근육이 이완 상태로 돌아갈 수 있어야 한다. 그러나 회복할 수 있는 기회가 거의 없이 반복적으로 발화(repeated firing)되거나 스트레스 반응에 대한 처리를 완료할 수 없다면, 스트레스 반응의 부적응적 조건화가 발생하여 이완할 수 없게 되고 그 결과 몸이 긴장상태로 유지되는 반응이 시작되며, 시간이 지남에 따라 축적되어 불안을 유발하게 된다[13]. 결과적으로 이 신경 에너지는 생리적, 심리적, 감정적 및 행동적 모든 수준에서 부적응적인 기능의 근본 원인이 된다.

Berceli[11]에 따르면, 유일한 해결책은 자율신경계(ANS; autonomic nervous system)에 갇힌 잔류 에너지를 방출(discharge)하는 것이라고 제안한다. 이는 말 그대로 떨림을 통해 요근을 풀어서 갇혀있는 에너지를 밖으로 내보내야 함을 의미한다. 이 방출은 실제로 떨림의 자발적인 활성화이며 TRE로 유도될 수 있는 회복 메커니즘을 나타낸다. 그는, 변연계, 자율신경계 및 뇌간 회로에서 발생하는 신경성 떨림이 스트레스와 외상의 경험에 반응하여 활성화된다고 주장한다. 따라서 자율신경계의 교감신경 분열에 의해 동원된 억눌린 에너지를 방출하여 싸움, 도피 또는 동결 반응의 완료를 허용할 뿐만 아니라 근육 긴장의 깊은 패턴을 방출하고 이완으로 돌아갈 필요가 있다. 이것은 신경성 떨림이 내장 감각과 감각 정보 과정을 수정하는 잠재적 능력을 말한다.

\section{3. 연구방법}

\section{1 연구대상 및 자료수집}

본 연구의 대상은 저자가 속한 학교의 대학원생 25명(40대 50대)이다. 저자는 트라우마 워크샵에 참석하였다가 우연히 TRE강사를 알게 되었고 직접 체험해보고 싶은 호기심에 강사에게 개별 워크삽을 요청하여 학생들과 함께 3시간 정도 체험하게 되었다. 25 명이라는 소수의 인원이지만 간략하게라도 훈련의 효과를 측정하기 위해 훈련 전에 상태불안검사를 실시하였고, 훈련 후에 다시 상태불안 검사를 실시하여 자료를 수집하였다.

\section{2 측정도구}

본연구에서 사용된 측정도구는 상태불안(STAI)척도이다. 불안의 정도를 측정하기 위해 Spielberger(1983)의 상태 특성불안검사(Y형STAI-Y; State-Trait Anxiety Inventory Y Form) 가운데 상태불안(State Anxiety)을 측정하는 20문항을 사용하였다. STAI Y형은 상태불안과 기질불안을 함께 측정할 수 있는 간편하고 객관적인 자기보고형의 단일척도로서 Spielberger, Gorsuch, 및 Lushene에 의해서 1964년부터 착수되었고 1970년 상태특성불안검사X형 (STAI-X; State-Trait Anxiety Inventory X Form)을 보완하여 1983 년 Spielberger 에 의해 완성되었다. 기질불안은 개인차를 지닌 동기와 획득된 성향으로 평소에 자신이 지니고 있는 비교적 변하지 않는 지속적인 것인 반면, 상태 불안은 시간의 변화에 따라 그 강도가 변화하는 것으로 주관적, 의식적으로 지각된 
감정에 따라 개인이 환경을 지각하여 특수 상황에서 느끼는 불안을 의미하는 것이다. 상태불안은 불안이 있는 상태를 의미하는 10 개의 부정적 문항과 불안이 없는 상태를 의미하는 10 개의 긍정적 문항으로 총 20 문항으로 되어 있으며 각 문항은 Liker식의 4 점 척도로 되어있다. 점수는 최저 20점에서 최고 80점까지이며 점수가 높을수록 불안 정도가 높은 것을 의미한다. 상태불안은 신뢰도가 (Cronbach's Alpha 계수로) $a=.86$ 이다. 국내에서 본 도구의 표준화 작업이 한덕웅, 이장호, 전겸구[19]에 의해 이루어 졌으며 신뢰도는 Cronbach's Alpha 계수로 $a=.92$ 였다

\section{3 자료분석}

집단내의 변량을 알아보기 위해 상태불안 측정값에 대해 paired-t 검정을 수행했다. 동일한 피험자들을 치료 전과 후에 두 번 검사하였다. 기술 통계를 포함한 모든 데이터 분석에는 SPSS가 사용되었으며, 통계적으로 허용 가능한 $95 \%$ 신뢰 구간이 모든 분석에 사용되었다.

\section{4. 결과}

상태불안 척도에 대해 대응표본 $\mathrm{t}$-검정(paired-t test)이 사용되었으며, 그 결과는 [표 1], [표 2], [표 3]에 제시되어 있다.

[표 1] 상태불안에 대한 TRE전후 평균, 표준편차 및 paired-t검증

[Table 1] Mean, Standard Deviation, and Paired-t Test Before and After TRE for State Anxiety

\begin{tabular}{|c|c|c|c|c|c|c|}
\hline \multirow{2}{*}{ 변인 } & \multirow{2}{*}{ 구분 } & \multicolumn{2}{|c|}{ 훈련 전 } & \multicolumn{2}{|c|}{ 훈련 후 } & paired-t \\
\cline { 2 - 7 } & & Mean & $\mathrm{SD}$ & Mean & $\mathrm{SD}$ & value \\
\hline \multirow{2}{*}{ 상태불안 } & 긍정 & 2.50 & .56 & 3.30 & .42 & $5.93^{* * *}$ \\
\cline { 2 - 7 } & 부정 & 1.82 & .56 & 1.18 & .29 & $7.15^{* * *}$ \\
\hline
\end{tabular}

먼저, 상태불안 긍정문항의 경우, 훈련 전 평균 2.50 에서 훈련 후 평균 3.30 으로, 유의미한 수준 $(\mathrm{t}=5.93, \mathrm{p}<.001)$ 에서 향상된 것으로 나타났다. 상태불안의 부정문항의 경우에도, 훈련 전 평균 1.82 에서 훈련 후 평균 1.18 로, 유의미한 수준 $(\mathrm{t}=7.15$, $\mathrm{p}<.001)$ 으로 감소한 것으로 나타났다. 이러한 결과는 TRE가 상태불안(STAI)에 긍정적인 영향을 미치는 것으로 해석할 수 있다.

[표 2] 상태불안(긍정) 각 문항에 대한 TRE 전후 평균, 표준편차 및 paired-t검증

[Table 2] Mean, Standard Deviation, and Paired-t test Before and After TRE for Each Item of State Anxiety (Positive)

\begin{tabular}{|c|l|c|c|c|c|c|}
\hline \multirow{2}{*}{ 변인 } & \multirow{2}{*}{ 문항 } & \multicolumn{2}{|c|}{ 훈련 전 } & \multicolumn{2}{c|}{ 훈련 후 } & paired-t \\
\cline { 3 - 8 } & & Mean & $\mathrm{SD}$ & Mean & $\mathrm{SD}$ & \\
\hline \multirow{2}{*}{$\begin{array}{c}\text { 상태불안 } \\
\text { (긍정) }\end{array}$} & 1. 나는 평온하다 & 2.44 & .82 & 3.28 & .61 & $5.25^{* * *}$ \\
\cline { 2 - 8 } & 2. 나는 안전하다 & 3.04 & .78 & 3.44 & .58 & $2.61^{*}$ \\
\cline { 2 - 7 } & 3. 나는 편안함을 느낀다. & 2.32 & .74 & 3.32 & .62 & $4.80^{* * *}$ \\
\hline
\end{tabular}




\begin{tabular}{|c|c|c|c|c|c|}
\hline 4. 나는 흡족하다. & 2.48 & .91 & 3.32 & .55 & $3.79^{* * *}$ \\
\hline 5. 나는 포근함을 느낀다. & 2.32 & .98 & 3.20 & .64 & $3.38^{* *}$ \\
\hline 6. 나는 자신감이 있다. & 2.60 & .64 & 3.28 & .61 & $4.23^{* * *}$ \\
\hline 7. 나는 느긋한 기분이다. & 2.44 & .82 & 3.28 & .61 & $4.67^{* * *}$ \\
\hline 8. 나는 만족스럽다. & 2.56 & .71 & 3.44 & .50 & $5.28^{* * *}$ \\
\hline $\begin{array}{l}\text { 9. 나는 마음이 동요되지 않고 안정되어 } \\
\text { 있다. }\end{array}$ & 2.32 & .69 & 3.24 & .77 & $4.43^{* * *}$ \\
\hline 10. 나는 유쾌하다. & 2.56 & .86 & 3.24 & .72 & $3.77^{* * *}$ \\
\hline
\end{tabular}

[표 3] 상태불안(부정) 각 문항에 대한 TRE 전후 평균, 표준편차 및 paired-t검증

[Table 3] Mean, Standard Deviation, and Paired-t Test Before and After TRE for Each Item of State Anxiety (Negative)

\begin{tabular}{|c|c|c|c|c|c|c|}
\hline \multirow{2}{*}{ 변인 } & \multirow{2}{*}{ 문항 } & \multicolumn{2}{|c|}{ 훈련 전 } & \multicolumn{2}{|c|}{ 훈련 후 } & \multirow{2}{*}{$\frac{\text { paired-t }}{\text { value }}$} \\
\hline & & Mean & SD & Mean & SD & \\
\hline \multirow{10}{*}{$\begin{array}{l}\text { 상태불안 } \\
\text { (부정) }\end{array}$} & 1. 나는 긴장되어 있다. & 2.16 & .68 & 1.32 & .69 & $4.25^{* * *}$ \\
\hline & 2. 나는 긴장감을 느낀다. & 2.12 & .66 & 1.24 & .52 & $6.06^{* * *}$ \\
\hline & 3. 나는 언짢다. & 1.36 & .56 & 1.12 & .33 & $2.75^{* *}$ \\
\hline & $\begin{array}{l}\text { 4. 나는 닥쳐올지도 모르는 불행을 지금 } \\
\text { 걱정하고 있다. }\end{array}$ & 1.80 & 1.0 & 1.40 & .86 & 2.00 \\
\hline & 5. 나는 두렵다. & 1.52 & .65 & 1.16 & .37 & $3.16^{* *}$ \\
\hline & 6. 나는 초조하다. & 1.64 & .70 & 1.12 & .43 & $4.43^{* * *}$ \\
\hline & 7. 나는 안절부절하다. & 1.52 & .71 & 1.04 & .20 & $3.67^{* * *}$ \\
\hline & 8. 나는 무엇을 해야 좋을지 모르겠다. & 1.64 & .81 & 1.08 & .27 & $3.64^{* * *}$ \\
\hline & 9. 나는 걱정이 많다. & 1.96 & .67 & 1.24 & .43 & $6.64^{* * *}$ \\
\hline & 10. 나는 혼란스럽다. & 1.68 & .62 & 1.12 & .33 & $4.80^{* * *}$ \\
\hline
\end{tabular}

\section{5. 논의 및 결론}

본 연구의 목적은 최근 Berceli가 개발한 TRE운동법이 긴장과 스트레스 그리고 트라우마를 해소하는 효과가 있는지를 검증하기 위한 하나의 pilot 연구로, TRE의 원리와 방법에 대해 간략히 소개하고 25 명의 성인 대학원생을 대상으로 TRE가 상태불안을 감소시키는지를 탐색하는 것이다. 이에 연구결과를 요약하고 논의하면 다음과 같다.

TRE는 Berceli가 최근에 개발한 긴장, 스트레스 및 트라우마 해소를 위한 운동법이다. Berceli는 20년 이상을 빈곤, 폭력, 전쟁과 자연재해 등으로 피폐해진 여러 나라에서 거주하면서 일해왔으며, 이 경험을 바탕으로 트라우마가 인간에게 미치는 영향에 대한 이해와 이를 해소하기 위한 연구 과정에서 트라우마 해소 운동인 TRE를 개발하였다.

그의 경험과 연구 결과에 의하면 이 운동법은 안전하고 누구나 배우기 쉬우며 그 효과는 광범위한 영역에서 나타나는 것으로 보고된다. 또한, 수면의 질을 개선하고, 스트레스 수준을 감소시키며, 근심, 걱정, 불안뿐 아니라 심각한 PTSD의 과각성을 
감소시키는 효과가 있다. 그러나 연구가 아직은 많지 않고 일화적 보고 또는 일부 pilot 연구를 포함하여 연구가 전 세계적으로 진행되고 있기에 정확한 메카니즘과 효과에 대해서 일반화하기에는 신중을 기해야 할 필요가 있다.

최근 이루어진 생물학, 신경생물학, 신체 심리학 및 외상학을 포함한 학제적인 연구결과에 의해 TRE의 원리 및 효과를 설명할 수 있다. 대표적인 학자로 Levin, Scaer 그리고 Berceli[10][11][13]에 의하면, 야생동물의 경우 주기적으로 포식자들로부터 생명의 위협을 받음에도 불구하고 이들이 트라우마가 없는 이유를 신경학적 떨림에 그 원인을 두고 있다. 야생동물들은 위협에서 벗어나면 뇌간에서 시작되는 신경성 떨림(neurogenic tremors)이라는 현상을 보이는데, 이 신경성 떨림을 통하여 자율신경계가 싸움(fight)또는 도망(flight)을 위해 준비한 과도한 에너지를 몸 밖으로 방출하게 되는데, 이 에너지가 방출되지 못할 경우 에너지는 신경계에 갇히게 되고 이는 곧 스트레스와 트라우마의 원인으로 작용하게 된다고 본다.

인간 역시 하나의 동물로 이러한 신경학적 메카니즘을 가지고 있으나 사회화되는 과정에서 몸을 떨거나 손과 발이 떨리는 것은 약함의 징표로 여기고 이를 억제하도록 교육받아왔기 때문에 뇌간에서 출발한 떨림을 피질이 억제하려고 노력하기도 하면서 온전한 방출이 일어나지 않으며, 따라서 트라우마 증상을 겪게 된다고 본다. Levine과 Scaer 그리고 Berceli[10][11][13]는 떨림은 인간이 타고난 적응 메카니즘이므로 떨림을 억제할 것이 아니라 몸이 가지고 있는 지혜로움에 맡기고 떨림이 자연스럽게 일어나도록 허용하는 분위기를 만들어줄 필요가 있다고 한다. TRE는 이런 자연스러운 떨림을 유도하는 운동법이다.

25 명의 대학원생을 대상으로 TRE 운동법이 상태불안에 미치는 효과를 살펴본 결과, $\mathrm{TRE}$ 는 상태불안을 긍정적으로 감소시키는 것으로 나타났다. 이러한 본 연구의 결과를 상태불안 관련한 기존의 연구들과 비교하기 위해 탐색한 결과, 단 한 건의 연구[20]를 찾을 수 있었다. $\mathrm{McCann}$ 의 연구에서 TRE를 체험한 집단에서 불안점수가 유의미하게 감소한 것으로 나타나 본 연구의 결과와 일치되는 결과를 보여주고 있다. McCann은 그의 논문에서 4 일간의 집중적인 $\mathrm{TRE}$ 입문 과정인 레벨 1 교육 과정에 참여하면 불안이 감소하고 주관적 웰빙과 삶의 질이 개선될 수 있음을 보고하였다.

$\mathrm{TRE}$ 관련 국내연구는 아직 한 편도 없는 실정이고 해외 연구도 아직 미미한 상황이지만 본 연구의 한계점과 관련하여 향후 연구 방향을 제시하고자 한다.

먼저, 본 연구의 실험설계는 통제집단의 부재로 인해 종속변수의 변화에 대해 인과적 설명을 할 수 없다는 한계점을 갖는다. 향후 연구에서는 실험집단에 대한 통제집단을 설정하여 인과관계를 추론할 수 있는 설계가 이루어지기를 기대한다.

연구대상 관련하여 언급하면, 본 연구의 대상자가 대학원 석사과정 또는 박사과정 학생들이었다는 점에서 이들은 정신적으로 그리고 육체적으로 비교적 건강한 모집단 표본으로 볼 수 있다. 차후에는 다양한 집단을 대상으로 연구가 이루어지기를 기대한다. 또한, 본 연구에서는 남녀 비율의 불균형 때문에, 성별에 따른 차이를 탐색할 수 없었다. 떨림의 메카니즘은 일반적으로 인간 종에 타고난 것으로 추정되며, 이는 성별에 관계없이 잠재적인 치료적 가치가 있음을 시사한다. 그럼에도 불구하고 성별에 따른 차이는 생물학적, 심리적, 감정적, 행동적으로 나타날 수 있다. 예를 들어, 운동은 남성의 정신과 비교하여 여성의 정신에 다르게 영향을 미칠 수 있다[11].

상태불안 감소에 대한 보다 포괄적인 설명을 위해 혈액, 타액 그리고 뇌파 분석과 같은 생리학적 측정 또는 관찰자 보고와 같은 보다 신뢰할 수 있는 객관적 측정 지표를 
포함하는 연구의 필요성이 제기된다.

마지막으로, 본 연구는 탐색적 성격을 갖는다는 측면에서 사실보다는 추론적 특성을 포함하고 있음을 밝힌다. 이는 현재 TRE 및 신경성 떨림에 대한 연구가 부족함을 의미하며, Berceli[11]가 진화, 신경 생물학, 인지 신경 과학, 신경 심리학 및 외상학과 같은 다양한 학문 분야를 섭렵하고 있다는 사실은 TRE 및 신경성 떨림의 치료적 가치에 대한 연구를 위해 학제 간 협력과 통합의 필요성을 의미한다.

종합하면, 근육의 이러한 떨림은 인간의 생존을 위한 자연치유력으로 긴장과 스트레스 수준을 낮추어 깊은 이완을 유발하기 때문에, 가벼운 속상함부터 직장 스트레스, 과도한 걱정, 인간관계 갈등, 신체적 스트레스, 트라우마로 인한 심한 불안까지 해소할 수 있는 유용한 도구이다. 떨림을 자연스럽게 유도하는 TRE는 안전하고 배우기가 쉬우며 한 번 배우면 평생 필요에 따라 독립적으로 사용할 수 있는 자조 도구로 개인의 정신적 신체적 건강을 지속적으로 지원하고 증진할 수 있다는 측면에서 그리고 인류 보편적이라는 측면에서 혁신적인 운동법이라고 할 수 있다. 그러나, 아직은 엄격하게 구조화된 실험설계를 통한 연구 결과보다는 많은 일화적 증거와 pilot 임상 결과 연구, 그리고 전 세계적으로 그 효능에 대한 연구가 일부 진행 중이라는 점을 고려하여 조심스러운 해석이 요구되며, 앞으로 통제된 양적 및 질적 연구가 더 필요하다.

\section{References}

[1] B. A. van der Kolk, Clinical Implications of neuroscience research in PTSD, Annals of the New York Academy of Sciences, (2006), Vol.1071, No.1, pp.277-293, DOI: 10.1196/annals.1364.022

[2] Stephen W. Porges, Orienting in a defensive world: Mamalian modifications of our evolutionary heritage: A polyvagal theory, Psychophysiology, (1995), Vol.32, No.4, pp.301-318.

[3] R. Scaer, The body bears the burden: Trauma, dissociation and disease, Hawthorn Press, (2001)

[4] Peter A. Levine, Gabor Maté, In an unspoken voice: How the body releases trauma and restores goodness, North Atlantic Books, (2010)

[5] P. Ogden, K. Minton, Sensorimotor psychotherapy: One method for processing traumatic memory, Traumatology, (2000), Vol.6, No.3, pp.149-173, DOI: 10.1177/153476560000600302

[6] E. T. Gendlin, Experiencing: A variable in the process of therapeutic change, American Journal of Psychotherapy, (1961), Vol.15, No.2, pp.232-245, DOI: 10.1176/APPI.PSYCHOTHERAPY.1961.15.2.233

[7] F. S. Perls, Gestalt Therapy Verbatum, Real People Press, (1969)

[8] A. Lowen, L. Lowen, The way to vibrant health: A manual of bioenergetic exercises, Harper \& Row, (1977)

[9] D. Berceli, Neurogenes Zitten: eine korperorientierte behandlungsmethode fur traumata in grossen bevolkerungsgruppen, (Neurogenic tremors -- The use of body--based interventions for mass trauma recovery.), Trauma \& Gewalt, (2010a), Vol.4, No.2, pp.148-157.

[10] R. Scaer, The trauma spectrum: Hidden wounds and human resiliency, W.W. Norton \& Company, (2005)

[11] D. Berceli, The Revolutionary Trauma Release Process: Transcend Your Toughest Times, Namaste Publishing, (2008)

[12] M. Cardinale, C. Bosco, The use of vibration as an exercise intervention, Exercise and Sport Sciences Reviews, (2003), Vol.31, No.1, pp.3-7, DOI: 10.1097/00003677-200301000-00002

[13] P. A. Levine, Waking the tiger: Healing trauma: The innate capacity to transform overwhelming experiences, North Atlantic Books, (1997) 
[14] H. Selye, The Stress of life, McGraw-Hill, (1956)

[15] D. Berceli, Evaluating the effects of stress reduction exercises employing mild tremors: a pilot study, Arizona State University, Ph.D dissertation, (2009)

[16] A. N. Schore, Dysregulation of the right brain: a fundamental mechanism of traumatic attachment and the psychopathogenesis of posttraumatic stress disorder, Australian and New Zealand Journal of Psychiatry, (2002), Vol.36, No.1, pp.9-30, DOI: 10.1046/j.1440-1614.2002.00996.x

[17] D. Berceli, M. Napoli, A proposal for a mindfulness--based trauma prevention program for social work professionals, Complimentary Health Practice Review, (2006), Vol.11, No.3, pp.153-165, DOI: 10.1177/1533210106297989

[18] L. Koch, The Psoas Book, Guinea Pig Publications, (1997)

[19] Deok-woong Han, Jang-ho Lee, Gyeom-goo Jeon, Korean Adaptation of Spielberger's STAI (K-STAI), Korean Journal of Health Psychology, (1995), Vol.1, No.1, pp.1-14.

[20] T. McCann, An evaluation of the effects of a training program in Trauma Releasing Exercises on quality of life, University of Cape Town, Master's thesis, (2011) 